\title{
On an improved sub-regional water resources management representation for integration into earth system models
}

\author{
N. Voisin, H. Li, D. Ward, M. Huang, M. Wigmosta, and L. R. Leung \\ Pacific Northwest National Laboratory, 902 Battelle Blvd, Richland, WA 99354, USA \\ Correspondence to: N. Voisin (nathalie.voisin@pnnl.gov) \\ Received: 11 February 2013 - Published in Hydrol. Earth Syst. Sci. Discuss.: 15 March 2013 \\ Revised: 1 August 2013 - Accepted: 12 August 2013 - Published: 30 September 2013
}

\begin{abstract}
Human influence on the hydrologic cycle includes regulation and storage, consumptive use and overall redistribution of water resources in space and time. Representing these processes is essential for applications of earth system models in hydrologic and climate predictions, as well as impact studies at regional to global scales. Emerging large-scale research reservoir models use generic operating rules that are flexible for coupling with earth system models. Those generic operating rules have been successful in reproducing the overall regulated flow at large basin scales. This study investigates the uncertainties of the reservoir models from different implementations of the generic operating rules using the complex multi-objective Columbia River Regulation System in northwestern United States as an example to understand their effects on not only regulated flow but also reservoir storage and fraction of the demand that is met. Numerical experiments are designed to test new generic operating rules that combine storage and releases targets for multipurpose reservoirs and to compare the use of reservoir usage priorities and predictors (withdrawals vs. consumptive demands, as well as natural vs. regulated mean flow) for configuring operating rules. Overall the best performing implementation is with combined priorities rules (flood control storage targets and irrigation release targets) set up with mean annual natural flow and mean monthly withdrawals. The options of not accounting for groundwater withdrawals, or on the contrary, of assuming that all remaining demand is met through groundwater extractions, are discussed.
\end{abstract}

\section{Introduction}

Earth system models (ESMs) are increasingly important tools for predicting future changes in the earth system. As water integrates many processes in both the natural and human components of the earth system, ESMs must accurately represent all branches of the hydrologic cycle; atmosphere, land, ocean, and human systems which includes water and energy infrastructures and management and socioeconomics. Human influence on the hydrologic cycle includes regulation and storage, consumptive use and overall redistribution of water resources in space and time. Representing these processes is essential for applications of ESMs in hydrologic and climate predictions, as well as assessing strategies for climate mitigation and adaptation at regional to global scales.

Water resources models used by operators and researchers at the basin scale include softwares with link-node architecture like RiverWare (Zagona et al., 2001), MODSIM (Labadie, 2005), OASIS (Sheer, 2000) and Water Evaluation and Planning System (WEAP) (http://www.weap21.org/), (Yates, 2005). Those Decision Support Systems (DSSs) are set up specifically, for one basin at the time. DSSs are datadriven and require from the user to specify inputs of specific operating rules, constraints and objectives specific for individual reservoirs: in forms of flood control rule curves; storage-release capacity for penstocks; controlled and uncontrolled releases; storage-stage and storage-surface area relationships; sector specific demands (hydropower, irrigation, supply, flood control management, etc); emergency release discharge - damage relationships; environmental restrictions in specific reaches, etc. Objective functions need to be specifically designed for each reservoir systems and goals need 
to be weighted based on the usages and priorities. Those reservoir operating rules are complex and not available for reservoirs worldwide. DSSs also require the knowledge of future flow for the optimizer to perform hundreds of simulations and derive optimized releases. They are presently not suitable for 2-way coupling with distributed ESMs. Multiple large-scale water resources models have been developed (Hanasaki et al., 2006; Haddeland et al., 2006a) and integrated at various levels of coupling into land surface hydrology models in order to evaluate the anthropogenic influences on the continental and global water cycles (Haddeland et al., 2006b, 2007; Doell et al., 2009; Biemans et al., 2011; Pokhrel et al., 2012a), including sea level rise (Pokhrel et al., 2012b). Those models differ from the DSSs in that detailed operating rules mentioned are not required. Some models have adapted the dynamic programming approaches that have been widely used in DSSs to optimize operations of reservoir systems at local and regional scales. For example, Haddeland et al. (2006a) developed an offline reservoir model combined with a crop evaporative demand module integrated into a macro-scale semi-distributed hydrology model. Their approach dynamically optimizes reservoir releases and requires accurate knowledge of future flow and demand for the upcoming water year, making it challenging for full integration with a land surface model. Other emerging large-scale research reservoir models use generic operating rules (no optimization) that are more flexible for coupling with ESMs because they do not need the subjective and specific rules of individual reservoirs nor do they need the knowledge of future flow for optimization and computation of releases. Hanasaki et al. (2006) developed "generic monthly operating rules" which are set up for each individual reservoir. These rules are based on the hydrometeorological conditions of the contributing area, the purposes of the reservoir and its physical characteristics, and the observed water withdrawals of the downstream domain of each reservoir. Those generic operating rules allow the potential for the reservoir models to be fully integrated into ESMs as they assume no knowledge of future inflow so simulations only need to be performed prognostically once for each time step. Those generic operating rules have been successful in reproducing the monthly regulated flows at large basin scales. Hanasaki et al. (2006) defined two types of reservoir operations in their model. Reservoir releases for irrigation are based on the mean annual and monthly natural flow, and the monthly demand anomaly with respect to the mean annual demand. Reservoir releases for other purposes are based on the mean annual natural inflow. Annual variability in the releases is based on the storage level at the beginning of the operational year. When a reservoir has multiple purposes, flood control has priority, then irrigation. In order to "set up" the reservoir releases, a land surface model is first applied to derive the natural inflow climatology into the reservoirs. Observed withdrawals are used to derive the long-term water demand climatology for the reservoirs.
The approach of Hanasaki et al. (2006) has been used as the basis for various improvements in the recent years. Hanasaki et al. (2008a, b) improved their previous reservoir module with an environmental flow module and integrated it into a simple bucket model coupled with a routing model. Validation was performed with respect to observed regulated flow. Doell et al. (2009) improved the Hanasaki et al. (2006) reservoir module by defining the reservoir operations based on the mean annual natural flow adjusted for the difference between precipitation and annual evaporation over the reservoirs. The reservoir storage is also constrained to not fall below $10 \%$ of the maximum capacity even for minimum flow, which is an estimate for the dead storage which cannot be released. The module was integrated into a land surface model with an irrigation module to evaluate the effect of irrigation on evapotranspiration fluxes globally. The reservoir releases were set up using the simulated consumptive use from irrigated areas as specified in Siebert et al. (2005) rather than withdrawals. Validation of the simulations was performed through a comparison of the simulated regulated flow with observed regulated flow. Pokhrel et al. (2012a) leveraged from Hanasaki et al. (2008a) and substituted the hydrologic bucket model with a process-based hydrology model with an irrigation module (demand, extraction and irrigation). The integrated system has been validated by comparing the simulated and observed regulated flow, and comparing the simulated terrestrial water storage with the Gravity Recovery and Climate Experiment (GRACE) satellite observations. Biemans et al. (2011) modified the Hanasaki et al. (2006) reservoir module by: (i) using long-term mean annual and monthly regulated flows to set up the reservoir releases, (ii) using consumptive uses adjusted with countryvarying conveyance efficiency factors to mimic withdrawals, (iii) adding a virtual-storage that stores water available for extraction from the simulated releases and keeps it available for extraction for 5 days else is released into the river, (iv) fine tuning the operating rules to accommodate only irrigation demand and rivers with large monthly variability, (v) prioritizing irrigation releases over flood control releases. The module is fully integrated into a distributed land surface hydrology model with irrigation and routing models. Validation was performed with respect to observed regulated flow.

The extensions or modifications of the reservoir operations modules discussed above differ in part from the original rules developed by Hanasaki et al. (2006) in several aspects, including:

1. Priority of the rules: irrigation, or flood control. Priority to flood control rule may result in a good agreement with observed regulated flow at the outlet of river basins of diverse drainage area and storage capacities (Hanasaki et al., 2006, 2008a). But subsequent analyses focused on the irrigation needs and favored the irrigation rules (Biemans et al., 2011). 
2. Use of natural flow (Hanasaki et al., 2006, 2008; Pokhrel et al., 2012a; Doell et al., 2009) versus impounded flow (Biemans et al., 2011) for the derivation of the releases; The annual and monthly mean natural inflows can be simply derived from a prior routing model simulation without the regulation module, a pre-processing step. Biemans et al. (2011) used the regulated flow that was computed with an on-thefly $20 \mathrm{yr}$ moving monthly and annual mean inflows into reservoirs (Hester Biemans, personal communication, September 2012) in order to refine the interannual variability.

3. Use of consumptive use (Biemans et al., 2011; Pokhrel et al., 2012a; Doell et al., 2009; Hanasaki et al., 2008a, b) rather than withdrawals (Hanasaki, 2006) for representing the demand in the calibration of the reservoir releases. Withdrawals can be observed while deriving the consumptive use requires either a water demand/crop model or a set of multiple observations at the extraction and application points.

Other variations between those schemes include differences in the crop growth model and irrigation module, the land surface hydrology model, routing model, and assigning grid cell water demand to specific reservoirs.

The approach of Hanasaki et al. (2006) and the various enhancements summarized above have provided a useful framework for representing reservoir operations in ESMs. They can capture the overall differences in reservoir operations and their impacts on streamflow (Hanasaki et al., 2006; 2008a, b), terrestrial water storage (Pokhrel et al., 2012a), and evapotranspiration demand or consumptive use (Doell et al., 2009) across large river basins worldwide. However, water management can have important effects on the regional water cycle through changes in the evapotranspiration, which may modulate the spatial and temporal characteristics of precipitation and temperature through land-atmosphere feedbacks and subsequently alter water demand. Hence, in the context of a fully coupled ESM, there is a need to validate and improve the reservoir modules as well as to evaluate the uncertainties caused by differences in the generic rules at the subregional scale that could affect the integrated results in fully coupled models.

The objective of this study is to further evaluate the generic operating rules and identify uncertainties in the reservoir model at regional and subregional scales, and improve them across multiple reservoir uses, with the ultimate goal of improving hydrology and evapotranspiration fluxes within an integrated ESM. More specifically, we address the following questions:

- How well do the existing generic reservoir operation rules perform in a specific basin? What is the subregional performance of the reservoir module? Is a val- idation with respect to observed regulated flow sufficient to capture model performance at a regional scale?

- For large basins that are snowmelt controlled but also have extensive irrigation, are there potential benefits in combining irrigation and flood control operation rules?

- How sensitive are the reservoir modules to the priority in the operating rules?

- How sensitive are the reservoir modules to the use of natural versus regulated flow for calibration of the releases?

- How sensitive are the reservoir modules to the use of consumptive use rather than withdrawals for calibrating the reservoir releases?

To address these questions, we implement the reservoir model of Hanasaki et al. (2006) in a newly developed physically-based routing model by Li et al. (2013) combined with Biemans et al. (2011) operating rules. We vary the configurations of the reservoir model by (i) giving priority of reservoir uses in turns for either flood control or irrigation if they are designed for both purposes, (ii) deriving the operating rules based on regulated or natural annual flow, and (iii) consumptive use or withdrawals. We also complement the releases targets with storage targets, which are developed in this study, in order to combine flood control, irrigation and hydropower purposes. We validate the reservoir module and its sensitivities to different operating rules by evaluating not only the simulated regulated flow and reservoir storages, but also how well the observed consumptive demand is met. This approach allows us to isolate the sources of errors and uncertainties coming from the reservoir model and the hydrologic simulations. Our domain of interest for the assessment is the Columbia River Basin (CRB). CRB provides a good testbed for modeling reservoir operations because it has good records of naturalized and regulated flow, and is snowmeltdominated with large flood control operations that need to be combined with extensive irrigation, hydropower and environmental flows.

The following sections describe the modeling framework first, then the experimental approach Sect. 4 presents the results. Section 5 discusses other sources of uncertainties.

\section{Modeling framework}

Figure 1 presents the modeling framework for the implementation, validation and sensitivity analysis of the water resources model, called WM hereafter. To drive WM, a macroscale physically-based distributed hydrology model (here Variable Infiltration Capacity; Liang et al., 1994) is forced with an observed gridded meteorological dataset (Maurer et al., 2002) to simulate the daily distributed runoff and baseflow to be routed. Observed demand is provided by the United States Geological Survey (USGS). 


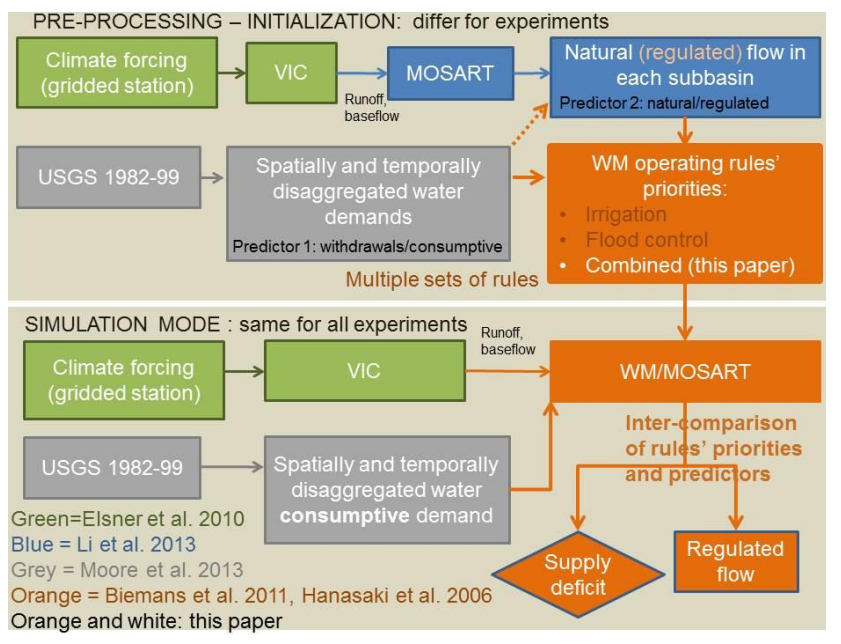

Fig. 1. A schematic presentation of the initialization and simulation modes of the WM/MOSART system, in its initialization and simulation modes, respectively.

The framework has two modes: initialization and simulation. In the initialization mode, the simulated runoff and baseflow are routed to derive inflow into each reservoir locations. Both flow and demand are used to set up the operating rules as a pre-processing step as detailed later. In simulation mode, however, WM is coupled to the routing model and is forced by distributed runoff and baseflow, and observed demand. This modeling framework is repeatedly used in all experiments in the paper, which differ only in the set up of the operating rules, i.e. the priority rule for each reservoirs and the predictors used to derive the operating rules of the reservoirs. This present section presents the hydrology model, the demand, and the reservoir model.

\subsection{Land surface hydrology}

The macroscale physically-based semi-distributed Variable Infiltration Capacity (VIC) hydrology model (Liang et al., 1994) solves the full water and energy balances of the land surface processes. The model represents subgrid spatial variability with a variable infiltration, subgrid elevation bands and a mosaic of vegetation types. We used the dataset of Elsner et al. (2010) to obtain daily simulated runoff and baseflow over the 1979-2005 period over the Columbia River Basin; VIC was forced with the gridded observed station meteorological dataset of Maurer et al. (2002) at 1/16th degree and daily time step with a parameter calibration performed with respect to naturalized observed flow. The 1/16th degree gridded daily simulated values are then projected to the subbasin representation of the Model for Scale Adaptive River Routing (MOSART, Li et al., 2013a). The subbasin representation preserves the natural boundaries of runoff accumulation and river system organization and has been compared with a gridded representation by $\mathrm{Li}$ et al. (2013b), showing comparable skill at similar resolutions. The routing model represents physical processes at multiple scales from hillslope routing toward a sub-network channel, baseflow interception by the subnetwork channel, and subnetwork channel routing into the main channel. The main channel facilitates the transport across subbasins using a kinematic wave approach. The reservoir model presented below is coupled to the routing model, but VIC is run offline, without enabling the irrigation capability (Haddeland et al., 2006a, 2007), to focus on our specific science questions related to reservoir operations.

\subsection{The observed consumptive demand}

The most comprehensive data on water use in the US are collected every five years by the United States Geological Survey agency (USGS) as part of the National Water Use Information Program. The most recent survey that is available is for 2005, but only includes withdrawals (Kenny et al., 2009). The 1995 USGS report (Solley et al., 1999) provides for each hydrologic region long-term mean annual estimates of withdrawals, consumptive use and conveyance losses. Moore et al. (2013) derived a gridded and monthly disaggregated USGS consumptive demand for each activity sector for 1982-1999 based on the annual values of the 1995 report. Consumptive use is defined for multiple sectors (public supply, industrial, irrigation, livestock, industrial, mining and thermoelectric power) and includes only the part of the water extraction that is not returned to the river through return flow including conveyance losses.

The total monthly consumptive demand time series is further temporally downscaled to a daily time scale using a uniform distribution and spatially projected to the sub-basin representation equivalent to the scale of the routing model (Fig. 2). Because the setup is not fully coupled to the land surface model in this experiment, only the total consumptive demand is used here.

\subsection{The water management model}

Figure 2 shows the work flow of WM, which is dynamically coupled to the routing model. Both models are run using the same time step, which can vary from minutes to days. In this experiment the inputs required by WM are daily runoff and baseflow independently simulated by the VIC hydrology model and the USGS daily total water consumptive demand. WM consists of an extraction module, reservoir-subbasin dependency databases, and operating rules.

\subsubsection{The extraction module}

For each subbasin, the surface runoff and baseflow are routed (hillslope) in a subnetwork by the routing model. The daily demand is first met by extracting water from the water storage in the subnetwork. The subnetwork flow is then routed into the subbasin main channel. The remaining demand is 


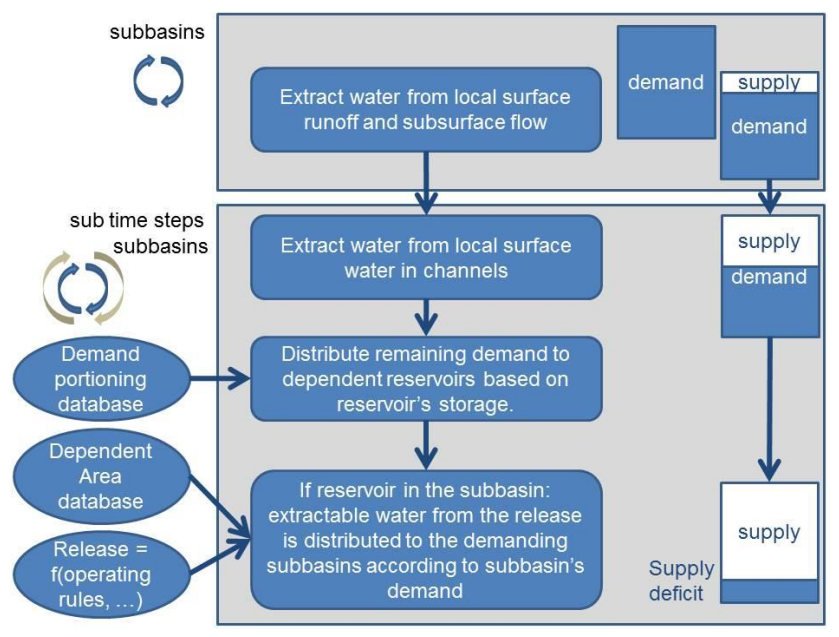

Fig. 2. Flow Chart of the water resources management model.

then extracted from the main channel water storage, with the constraint to leave at least $50 \%$ of the flow in the main channel for computational stability in the hydrodynamic routing model (sub time step within the subbasin). If the demand of the subbasin is still not fully met, the subbasin will request water from multiple reservoirs. The reservoirs from which that subbasin can request water is specified by the dependency database described next (i.e. portioning database). The demand to a specific reservoir is the remaining demand adjusted by the ratio of the storage in that reservoir to the combined storage of all reservoirs from which the subbasin can request water determined at the beginning of each month in the simulation. Conversely, the extractable water form the computed release consists of the release minus the minimum flow. That extractable water is distributed accross the demanding subbasins specified by the dependency database (i.e. dependent area). The supply is distributed to the demanding subbasins proportionally to the ratio between the demand of each each subbasins' demand and the total demand to that reservoir. In an offline mode like in this setup, the consumptive use is being extracted instead of withdrawals, which would be more appropriate in a fully coupled ESM in which the return flow would be simulated.

\subsubsection{The dependency databases}

The dependency database is developed to assign (i) to each reservoir a list of subbasins that can extract water from its release and (ii) the portioning of each subbasin's demand to a specific reservoir. The dependencies have been determined somewhat differently among previous studies.

\section{Dependent area}

Hanasaki et al. (2006) defined the dependent area as the downstream area of the reservoir down to the distance water can travel in the channel in one month. We adopted the approach equivalent to Biemans et al. (2011) and Haddeland et al. (2006a), which allows all downstream subbasins that have a mean elevation lower than the mean elevation of the subbasin where the reservoir is located, and are within a $200 \mathrm{~km}$ distance from the stem flowing from the reservoir to the outlet of the basin to extract water from the reservoir releases. Some errors can be introduced by neighboring lakes with no consequence, as they have no water demand.

\section{Demand portioning}

Each subbasin can request water from all the reservoirs determined by the dependency described above. For the initialization of the operating rules, the request to an individual reservoir is adjusted by the ratio of the capacity of the reservoir to the total capacity over all dependent reservoirs, equivalent to Haddeland et al. (2006a). In a simulation mode, instead of reservoir capacity the daily request to reservoirs is adjusted with respect to the storage (volume) of the reservoir at the start of the month, which is a slight modification from Biemans et al. (2011) who used running mean annual storage, and Hanasaki et al. (2006) who used the long term mean annual inflows for the portioning.

\subsubsection{The operating rules}

The reservoir model relies on generic operating rules detailed in Biemans et al. (2011) and Hanasaki et al. (2006) that described the original derivation of the rules. Briefly, target releases $\left(r^{\prime}\right)$ are pre-set for the different reservoir purposes.

For flood control, water supply, hydropower and navigation, the monthly pre-release $\left(r^{\prime} \mathrm{m}, \mathrm{yr}\right)$ is assumed to be constant and is the long-term (1982-1999) mean annual flow $\left(i_{\text {mean }}\right)$.

$r_{\mathrm{m}, \mathrm{yr}}^{\prime}=i_{\text {mean }}$

where " $m$ " and "yr" stands for month and year. For irrigation purposes, however, the pre-release becomes:

$$
\begin{aligned}
& r_{\mathrm{m}, \mathrm{yr}}^{\prime}=\frac{i_{\text {mean }_{\text {nat }}, \mathrm{m}}}{10}+\frac{9}{10} \cdot i_{\text {mean }} \cdot \frac{d_{\text {mean } \mathrm{m}}}{d_{\text {mean }}} \text { if } d_{\text {mean }, \mathrm{m}} \geq 0.5 i_{\text {mean }} \\
& r_{\mathrm{m}, \mathrm{yr}}^{\prime}=i_{\text {mean }}+d_{\text {mean }, \mathrm{m}}-d_{\text {mean }} \text { if } d_{\text {mean, } \mathrm{m}}<0.5 i_{\text {mean }} \\
& d_{\text {mean }, \mathrm{m}}=d_{\text {dom }, \mathrm{m}}+d_{\text {ind }, \mathrm{m}}+d_{\text {irr } \mathrm{m}}+d_{\mathrm{liv}, \mathrm{m}}+d_{\text {min }, \mathrm{m}} \\
& +d_{\text {pub }, \mathrm{m}}+d_{\text {thermo, } \mathrm{m}}
\end{aligned}
$$

where $\left(i_{\text {mean,nat, } m}\right)$ is the 1982-1999 mean monthly natural flow, $\left(d_{\text {mean }}\right)$ and $\left(d_{\text {mean,m }}\right)$ are the 1982-1999 long-term mean annual and monthly demand assigned to the reservoir respectively. The pre-release targets are then adjusted to include inter-annual variability. The start of the operational year is defined in Hanasaki et al. (2006) as the first month at which the long-term mean monthly flow falls below the longterm mean annual flow. If there are multiple such instances in 
the long-term mean monthly hydrograph, the month starting the longest period under the mean annual flow is selected. In each year (yr), at the beginning of this month $(\mathrm{m})$, the ratio $\left(k_{\mathrm{rls})}\right.$ of the reservoir storage $(S)$ over the reservoir's maximum capacity $(C)$ divided by an adjusting factor $(\alpha)$ of 0.85 will drive the interannual variability of the releases,

$k_{\mathrm{rls}}=S_{\text {first } \mathrm{yr}} / \alpha C$

Finally, the actual monthly releases $\left(r_{\mathrm{m}, \mathrm{yr}}\right)$ consist of the prereleases adjusted for interannual variability based on reservoir characteristics, as determined by:

$r_{\mathrm{m}, \mathrm{yr}}=\left\{\begin{array}{l}k_{\mathrm{rls}, \mathrm{yr}} * r_{\mathrm{m}, \mathrm{yr}}^{\prime}(c \geq 0.5) \\ \left(\frac{c}{0.5}\right)^{2} k_{\mathrm{rls}, \mathrm{yr}} * r_{\mathrm{m}, \mathrm{yr}}^{\prime}+\left\{1-\left(\frac{c}{0.5}\right)^{2}\right\} i_{\text {mean }, \mathrm{m}} \\ (0 \leq c \leq 0.5)\end{array}\right.$

with $c=\frac{C}{i_{\text {mean }}}$

If the maximum capacity of the reservoir is reached, then the daily release is increased, i.e. spilling occurs. Similarly, the releases are adjusted in order for a reservoir to not go below $10 \%$ of its maximum storage capacity, which can be below the minimum monthly flow if necessary.

If the reservoir is built for irrigation, then the prorated consumptive demand of all dependent subbasins is aggregated and can be extracted from the part of the reservoir release that is available for extraction (i.e. there is always a minimum of $10 \%$ of the mean monthly natural inflow that is released into the river downstream of the reservoir). Partitioning of the extraction to each subbasin is based on the ratio of the reservoir storage at the beginning of the month over the aggregated reservoir storage at the beginning of the month of all reservoirs that the subbasin depends on. Remaining extractable water is further distributed to dependent subbasins with unmet demand from other reservoirs, using a uniform ratio of remaining extractable water over the total initial demand to that reservoir.

\subsubsection{Improvements of the water resources model}

Previous set ups differ in the priority of the operating rules; Hanasaki et al. (2006) use the irrigation release targets only for reservoirs whose purposes include irrigation but not flood control. Otherwise priority is given to flood control. In contrast, Biemans et al. (2011) give priority to the irrigation rules even if the reservoir is also operated for flood control. As shown later, the irrigation and flood control priority rules both lead to large seasonal variations in the reservoir storages. A snowmelt-controlled basin, like the Columbia River Basin (Fig. 3), has multiple competitive uses. Rule curves are used in order to specifically drop the reservoir storages before snowmelt starts while maintaining the storage in the reservoir and provide releases for irrigation, water supply and hydropower in the remaining of the year. An accurate representation of reservoir storage is deemed important for future implementation in a land surface model coupled with

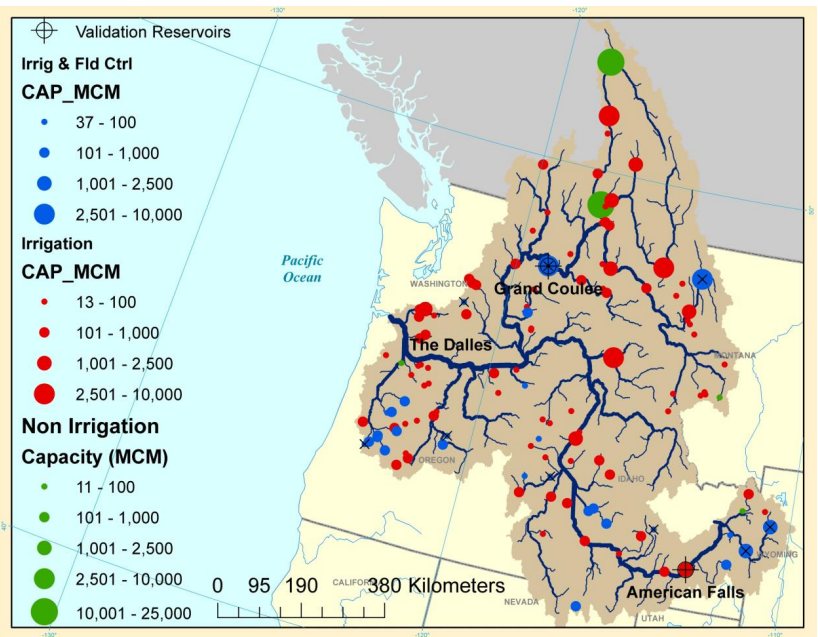

Fig. 3. 125 reservoirs of the GRanD database over the Columbia River Basin. Reservoirs used for irrigation among other uses but not flood control are displayed in red. Reservoirs used for irrigation and flood control are displayed in blue. Irrigation and flood control reservoirs to which combined rules could be applied are in orange. The reservoir module is validated at The Dalles, Grand Coulee, and American Falls. Size of the reservoirs is proportional to the reservoir capacities in millions cubic meters (MCM). The X identifies the Irrigation and Flood Control reservoirs most sensitive to the combined operating rules (Fig. 12).

an atmospheric model because the evaporation from reservoirs has been shown to potentially increase convective available potential energy (CAPE) (Degu et al., 2011), leading to changes in precipitation. It is also essential for hydropower simulation and for simulating stream temperature and other water quality components, which are critical for energy production considerations such as cooling water supply to power plants.

We investigate the potential improvement to combine flood control and irrigation generic operating rules by conserving the irrigation releases most of the year, but applying flood control rules before snowmelt. We develop flood control storage targets to complement the irrigation releases targets with mass balance conservation. The objective is to drop reservoir storage prior to the snowmelt peak, then fill up the reservoir with flow contributed with snowmelt, and maintain storage until the start of the operational year. We define the start and end of a flood control period using the long-term mean monthly hydrograph and going backward in time with respect to the start of the operational year defined in Sect. 3.2: the end of the flood control period (NDFC) is defined as the first month of the wet period preceding the start of the operational year (STOp), i.e. first month above the mean annual flow. The start of the flood control period (STFC) is defined as the month with the lowest flow within the dry period preceding the start of the operational period. It is arbitrarily constrained to 6 months before the end of the 


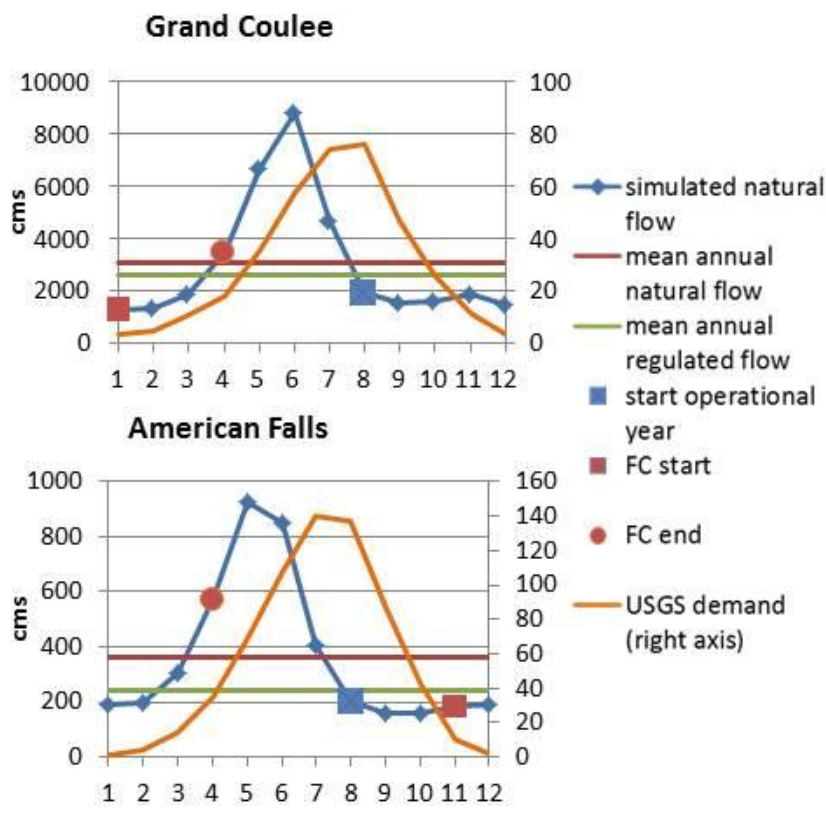

Fig. 4. Monthly and annual unregulated flow, annual impounded flow into Grand Coulee and American Falls reservoirs and monthly USGS observed consumptive demand associated with Grand Coulee and American Falls reservoirs and their upstream areas.

flood control season. Figure 4 shows a sample hydrograph with the position of the start and end of the flood control period with respect to the start of the operational year. During that flood control period, the estimated drop in storage that would have to occur with the flood control rule is computed.

Drop $=\sum_{\mathrm{m}=\mathrm{STFC}}^{\mathrm{m}=\mathrm{NDFC}-1}\left(i_{\text {mean }, \mathrm{m}}-i_{\text {mean }}\right)$

$r_{\mathrm{m}, \mathrm{yr}}=r_{\mathrm{m}, \mathrm{yr}}+\frac{\text { Drop }}{\text { Ndrop }}$

The planned irrigation releases (Eqs. 2 and 5) are then adjusted during that period with an additional release of the planned total drop adjusted for the number of months in the flood control period (Ndrop). This allows a linear drop in the storage for a smooth balance between maintaining storage and releasing flow for hydropower purposes. From NDFC to STOp, we ensure that the reservoir fills again for the irrigation season by releasing only the mean annual flow. Figure 5 illustrates the monthly pre-releases using predictors (inflow and demand) at Grand Coulee for different priorities (Eqs. 1 and 2, 2 and 5). Pre-release patterns are representative for all the reservoirs according to their specified uses.

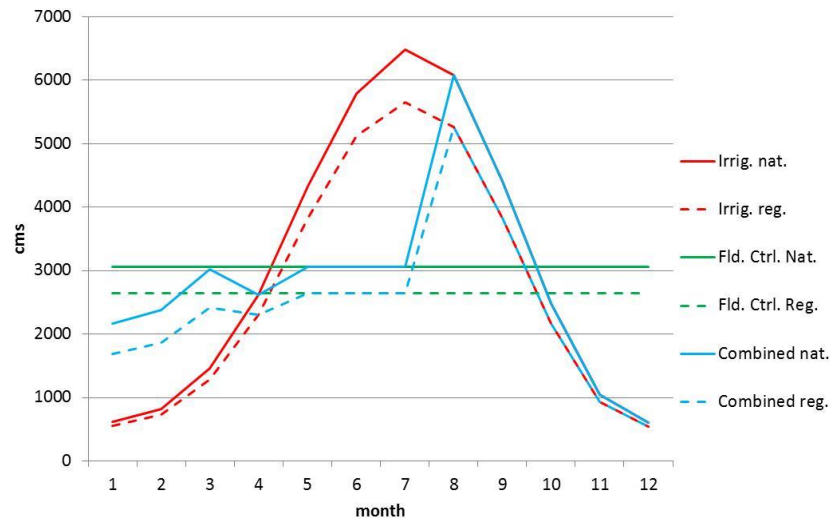

Fig. 5. Sensitivity of the pre-releases of Grand Coulee to different priorities and predictors.

\section{Experimental approach}

\subsection{Evaluation of the model}

The system is forced with observed demand, and observed meteorology using a distributed hydrology model with no irrigation component, calibrated with respect to observed naturalized flow. Errors in the hydrological modeling are quantified by the differences between the simulated natural flow and the naturalized observed flow. The errors between the observed regulated flow and the simulated regulated flow are due to a combination of errors in both the hydrology model and in the coupled water resources management routing model. Errors in the routing model are negligible at the monthly time scale of interest. Hence, we validate the reservoir module and its sensitivities to different operating rules by evaluating not only the simulated regulated flow and reservoir storages, but also how well the observed consumptive demand is met. This approach allows us to isolate the sources of errors and uncertainties coming from the reservoir model and the hydrologic simulations without the vegetation growth and irrigation module components.

\subsection{The Columbia River Basin}

The modeling system is applied to the Columbia River Basin (CRB, Fig. 3). CRB drains $668000 \mathrm{~km}^{2}$ into the North Pacific Ocean. It is the fourth largest river by volume in the United States of America and is snowmelt controlled. The north portion of the basin lies in British Columbia, Canada where reservoirs are used extensively for flood control, but also maintain the flow throughout the year to sustain high hydropower generation (16500 MW annual average) and extensive irrigation downstream (1.4 million hectares). The main tributary of the Columbia River is the Snake River $\left(280000 \mathrm{~km}^{2}\right)$, from which withdrawals are primarily used for irrigation. Overall, water extraction for diverse activity sectors is about $6 \%$ of the mean annual flow over the entire 


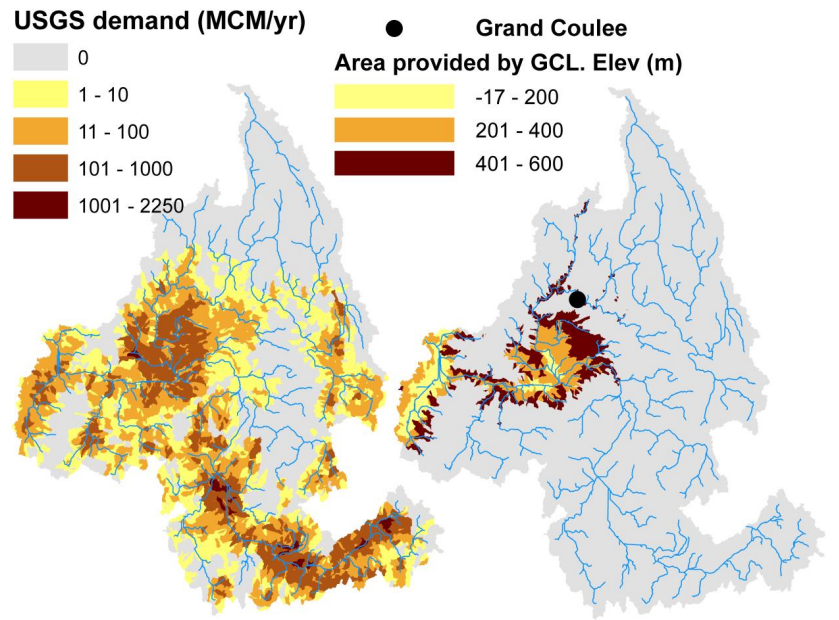

Fig. 6. (left) annual USGS total consumptive water demand (millions cubic meters - MCM) projected to the subbasins mask; (right) Subbasins dependent on Grand Coulee Reservoir.

basin and $23 \%$ for the Snake River only (Payne et al., 2004). Multiple locations in the basins are considered in this analysis in order to cover multiple reservoirs and hydroclimatic conditions. The station closest to the outlet of the basin is The Dalles. Model performance at The Dalles is representative of model skill at the regional scale. Grand Coulee dam is a massive construction along the main stem with most of the reservoirs upstream regulated for flood control. Grand Coulee is operated for flood control as well as hydropower and irrigation. Grand Coulee has a generating capacity of $6809 \mathrm{MW}$ and is operated by the Corps of Engineers in cooperation with Bonneville Power Administration. Figure 6 shows the estimated dependent area from Grand Coulee. American Falls is a reservoir along the Snake River Basin and is operated by the Bureau of Reclamation for irrigation and other uses but not including flood control. It is chosen because of its location on the Snake River, upstream of the large irrigation demand, and the availability of observed flow and storage observations.

The GRanD database (Lehner et al., 2011) provides the locations of the 125 reservoirs in the basin with their characteristics including date of completion, maximum capacity, surface area, height, and uses (flood control, irrigation, water supply, hydropower, fish, recreation, navigation). Of the 125 reservoirs, 77 are used in part for irrigation, of which 29 are used for both irrigation and flood control (Fig. 3). Runof-the-rivers reservoirs are not represented in the GRanD database. Figure 6 shows the dependent area (Sect. 2.3.1) of Grand Coulee. Figure 4 shows an example of the aggregated demand associated with Grand Coulee and American Falls and the reservoirs upstream of them. The assigned consumptive demand to be potentially fully extracted represents 13 and $33 \%$ of the simulated mean annual unregulated flow at Grand Coulee and American Falls, respectively. This is higher than the $6 \%$ over the entire basin and
$23 \%$ of the Snake River observed estimates because; (i) the simulated demand estimates to those reservoirs include the portion of the demand that will be met locally and ultimately will not be requested from the reservoir, (ii) they account for demand that would be met through groundwater withdrawals and (iii) some of the extractions are happening more upstream than expected by constructing the dependency database. This early reservoir withdrawal allows meeting more of the observed consumptive demand (see Pokhrel et al., 2012a results for a comparison with a dependency database constraining the grid cells to only extract from the first upstream reservoirs).

\subsection{Sensitivity analysis}

Table 1 presents the set up of the operating rules (priority and predictors) used in previous analyses (Hanasaki et al., 2008; Doell et al., 2009; Biemans et al., 2011). In order to address the scientific questions, we use an identical set up for all the reservoir model configurations (Fig. 1). The experiment differs in the operating rules only, as follows:

- Highest priority rule: irrigation or flood control or combined priorities.

- Use of either withdrawals or consumptive demand to set up the operating rules

- Use of natural or regulated annual mean flow to set up the operating rules

\subsubsection{Sensitivity to operating rules priorities}

As discussed in Sect. 3.2, out of 125 reservoirs considered in this study, 77 are for irrigation of which 29 are jointly operated for flood control and irrigation. Therefore, the change in usage priority only affects those 29 reservoirs. Of those 29 reservoirs, most (20) are in rain-snow transition basins with a first flow peak in the Fall succeeded by the Spring snowmelt with a couple months above the mean annual flow; the start of the flood control period as defined by the combined operating rules exceeds the eight months threshold prior to the start of the operational year and the rules could not be applied. Table 1 presents how the change in priority affects the operating rules equations for the different reservoir usage in the application basin. Figure 5 illustrates the change in the pre-release for Grand Coulee for different priorities.

\subsubsection{Sensitivity to predictors used to derive the operating rules}

In Eqs. (1), (2), (4) and (5) for deriving the operating rules, two predictors are used: flow, which can be either regulated or natural, and demand, which can be either consumptive demand or withdrawals. In Hanasaki et al. (2006), initial rules were developed using natural flow and withdrawals. Biemans et al. (2011) used regulated flow and adjusted consumptive 
Table 1. Reservoir operating rules by usage category for the three priority cases.

\begin{tabular}{llll}
\hline Scenario with priorities & $\begin{array}{l}\text { Irrigation and no flood control } \\
(48 \text { dams) }\end{array}$ & $\begin{array}{l}\text { Irrigation and flood control } \\
\text { (29 dams) }\end{array}$ & $\begin{array}{l}\text { No irrigation } \\
(48 \text { dams) }\end{array}$ \\
\hline $\begin{array}{l}\text { Priority to Irrigation (Irrig) } \\
\text { Priority to Flood control (Fld Ctrl) }\end{array}$ & $\begin{array}{l}\text { Irrigation rule (Eqs. 2, 3 and 4) } \\
\text { Irrigation rule (Eqs. 2, 3 and 4) }\end{array}$ & $\begin{array}{l}\text { Irrigation rule (Eqs. 2, 3 and 4) } \\
\text { Eqs. (1), (3) and (4) }\end{array}$ & $\begin{array}{l}\text { Eqs. (1), (3) and (4) } \\
\text { Eqs. (1), (3) and (4) }\end{array}$ \\
\hline
\end{tabular}

use to mimic withdrawals. Doell et al. (2009) used natural flow and consumptive uses. Table 2 specifies the operating rule equations for different predictors by usage category. Figure 5 illustrates the change in the pre-release for Grand Coulee for different priorities and flows.

Two types of demand are used in the different experiments: withdrawals $\left(d_{\text {mean }}=\overline{\mathrm{Wdraw}}\right)$, or consumptive use $\left(d_{\text {mean }}=\overline{\mathrm{Csum}}\right)$. Even though withdrawals datasets are available, they are simply derived from the consumptive uses (Eq. 7) since irrigation consumptive use is readily available from ESMs. Over the Pacific Northwest region, the USGS reported annual total (i.e. the sum of surface and groundwater, brackish and fresh water) withdrawals is 44200 millions cubic meter (MCM) for a consumptive use of $14600 \mathrm{MCM}$, giving a ratio of about 3 (Solley et al., 1999). We simply adjust this consumptive demand as to derive a withdrawal demand which is based on observed regional ratios between consumption and withdrawals:

$\overline{\mathrm{Wdraw}}_{\mathrm{m}}=\overline{\operatorname{Csum}}_{\mathrm{m}} * \frac{\mathrm{PNW} \text { total withdrawals }}{\mathrm{PNW} \text { total consumptive use }}$

As USGS observed consumptive demand is only available for 1982-1999, we do not use a $20 \mathrm{yr}$ running period but rather pre-process the 1982-1999 long term mean monthly and annual natural/regulated flow. The annual and monthly inflows are derived from a 1982-1999 routing model MOSART simulation forced with daily surface runoff and baseflow simulated by VIC. The annual regulated flow into a reservoir, however, is derived as the long-term mean annual natural inflow minus the mean annual long-term consumptive demand associated with all upstream reservoirs according to the dependency database. Maintaining $10 \%$ of the mean monthly flow is maintained for environmental concern is implemented using the mean monthly un-impounded flow. It slightly differs from Biemans et al. (2011) who used the mean monthly regulated flow, but also showed low sensitivity for fractions varying between 0 and $20 \%$. Note that despite withdrawals or consumptive uses are used to derive the operating rules, it is logical to only extract the consumptive use in the offline mode. This is identical to all experimental predictor set ups. We will address the increased uncertainties with increasing levels of coupling, and how withdrawals and consumptive demands are being combined in order to define an accurate estimate of the return flow in future work.
Table 3 summarizes the experiments for comparing multiple WM set ups with different priority rules and predictors: "nat" refers to operating rules derived from natural flow and withdrawals; "reg" to regulated flow and withdrawals; "reg consum" to regulated flow and consumptive use.

\section{Results}

The results section answers scientific questions. The first section evaluates WM at the regional and subregional scales. The second section demonstrates the improvement of the combined operating rules (baseline set up) with respect to the other priority rules. We also quantify the sensitivity of WM to priority rules used in previous analyses. The third section analyses the sensitivity of WM to predictors of the operating rules. The regional analyses on those sections consist of evaluating the simulated natural and regulated flows at the outlet of the basin, The Dalles, as well as the basin-scale supply deficit with respect to the observed consumptive use. At the subregional scale we also evaluate the simulated regulated outflow and reservoir storage at Grand Coulee and American Falls reservoirs. The supply deficit, or unmet demand, is computed for each subbasin as the difference between the consumptive demand and the supply.

\subsection{Evaluation of the model}

The baseline WM is using the combined irrigation-flood control rules as priority and natural flow and withdrawals as predictors. We validate the baseline WM at the regional and subregional scales.

\subsubsection{Flow}

Figure 7 shows the 1984-1999 mean monthly outflow and daily outflow time series at The Dalles, Grand Coulee and American Falls (green line). Flow validation and evaluation is performed by evaluating the errors in the regulated flow and the change in flow pattern from natural to regulated in order to isolate the reservoir operations performance from initial hydrologic simulation errors.

Table 4 presents performance metrics for the natural flow at the Dalles and regulated flow at The Dalles, Grand Coulee and American Falls. Driven predominantly by snowmelt, the natural flow in CRB peaks between May and June, which 
Table 2. Detailed operating rules for multiple predictor combinations.

\begin{tabular}{|c|c|c|c|}
\hline Predictors & $\begin{array}{l}\text { Flood Control Rule } \\
\text { (Eqs.1, } 2 \text { and 5) }\end{array}$ & $\begin{array}{l}\text { Irrigation Rule } \\
\text { (Eqs. 2, 3, 4, and 5) }\end{array}$ & $\begin{array}{l}\text { Combined } \\
\text { (Eqs. 1, 2, } 5 \text { and 6) }\end{array}$ \\
\hline $\begin{array}{l}\text { Withdrawals and } \\
\text { natural flow (nat) }\end{array}$ & $r_{\mathrm{m}}^{\prime}=\bar{i}_{\mathrm{NAT}}$ & $\begin{array}{l}\text { if } \overline{\mathrm{Wdraw}}_{\mathrm{m}} \geq 0.5 \bar{i}_{\mathrm{NAT}} r_{\mathrm{m}}^{\prime}=\frac{\bar{i}_{\mathrm{NAT}, \mathrm{m}}}{10}+\frac{9}{10} \cdot \bar{i}_{\mathrm{NAT}} \cdot \frac{\overline{\mathrm{Wdraw}}_{\mathrm{m}}}{\overline{\mathrm{Wdraw}}} \\
\text { else } r_{\mathrm{m}}^{\prime}=\bar{i}_{\mathrm{NAT}}+\overline{\mathrm{Wdraw}}_{\mathrm{m}}-\overline{\mathrm{Wdraw}}^{\text {Wdraw }}\end{array}$ & Drop $=\sum_{\mathrm{m}=\mathrm{STFC}}^{\mathrm{NDFC}-1}\left(r_{\mathrm{m}}-\bar{i}_{\mathrm{NAT}}\right)$ \\
\hline $\begin{array}{l}\text { Withdrawals and } \\
\text { regulated flow (reg) }\end{array}$ & $r_{\mathrm{m}}^{\prime}=\bar{i}_{\mathrm{REG}}$ & $\begin{array}{l}\text { if } \overline{\mathrm{Wdraw}}_{\mathrm{m}} \geq 0.5 \bar{i}_{\mathrm{REG}} r_{\mathrm{m}}^{\prime}=\frac{\bar{i}_{\mathrm{NAT}, \mathrm{m}}}{10}+\frac{9}{10} \cdot \bar{i}_{\mathrm{REG}} \cdot \frac{\overline{\mathrm{Wdraw}}_{\mathrm{m}}}{\overline{\mathrm{Wdraw}}} \\
\text { else } r_{\mathrm{m}}^{\prime}=\bar{i}_{\mathrm{REG}}+\overline{\mathrm{Wdraw}}_{\mathrm{m}}-\overline{\text { Wdraw }}\end{array}$ & Drop $=\sum_{\mathrm{m}=\mathrm{STFC}}^{\mathrm{NDFC}-1}\left(r_{\mathrm{m}}-\bar{i}_{\mathrm{REG}}\right)$ \\
\hline $\begin{array}{l}\text { Consumptive use and } \\
\text { regulated flow (reg } \\
\text { consum) }\end{array}$ & $r_{\mathrm{m}}^{\prime}=\bar{i}_{\mathrm{REG}}$ & $\begin{array}{l}\text { if } \overline{\operatorname{Csum}}_{\mathrm{m}} \geq 0.5 \bar{i}_{\mathrm{REG}} r_{\mathrm{m}}^{\prime}=\frac{\bar{i}_{\mathrm{NAT}, \mathrm{m}}}{10}+\frac{9}{10} \cdot \bar{i}_{\mathrm{REG}} \cdot \frac{\overline{\operatorname{Csum}}_{\mathrm{m}}}{\overline{\mathrm{Csum}}^{\prime}} \\
\text { else } r_{\mathrm{m}}^{\prime}=\bar{i}_{\mathrm{REG}}+\mathrm{Csum}_{\mathrm{m}}-\overline{\mathrm{Csum}}\end{array}$ & Drop $=\sum_{\mathrm{m}=\mathrm{STFC}}^{\mathrm{NDFC}-1}\left(r_{\mathrm{m}}-\bar{i}_{\mathrm{REG}}\right)$ \\
\hline
\end{tabular}

Table 3. Summary of the experiments used to assess the sensitivities to priorities, use of natural versus regulated flow, use of consumptive use versus withdrawals, and improvement of using combined priorities. The names of nine experiments with different combinations of predictors (flow, demand), and priorities are shown.

\begin{tabular}{llll}
\hline $\begin{array}{l}\text { Priorities } \rightarrow \\
\text { Predictors } \downarrow\end{array}$ & Irrigation & Flood Control & Combined \\
\hline Natural flow, withdrawals & Irrig nat & FC nat (Hanasaki et al., 2006) & combined nat \\
Regulated flow, withdrawals & Irrig reg (Biemans et al., 2011) & FC reg & combined reg \\
Natural flow, consumptive use & Not run (Doell et al., 2009) & Not run (Pokhrel et al., 2012) & Not run \\
Regulated flow, consumptive use & Irrig reg consum & FC reg consum & Combined reg consum \\
\hline
\end{tabular}

is well captured by the simulated natural flow with a correlation coefficient of 0.96 and a bias of $6 \%$. WM captures well the change in flow from natural to regulated with a correlation coefficient of 0.95 and a bias of $3 \%$ for the simulated regulated flow with respect to the observed regulated flow. At Grand Coulee the naturalized flow is not available and only regulated flow is evaluated with a correlation of 0.85 , an annual bias of $6 \%$ but a negative Nash Sutcliff Efficiency (NSE) coefficient due to an underestimated variance. At American Falls, the observed naturalized flow was available until 1992. The simulated natural flow agrees reasonable well with the observed naturalized flow with a correlation of 0.87 and the bias of $-9 \%$. NSE is low (0.24). The regulated spring snowmelt flow seems in a good agreement with observations with a correlation of 0.80 , although simulated regulated flows in the Summer are too low. The Upper Snake River basin region uses groundwater extensively for irrigation, which "augments" the observed regulated flow in Summer time. The modeling framework, VIC-MOSARTWM, does not account for groundwater supply so the overall simulated regulated flow underestimates the observed regulated flow in Summer time. However, the overall annual regulated flow overestimates observed regulated flow by $15 \%$ as a combination of overestimated demand to the reservoir and high interannual variability in the inflow as discussed next for consequences on the simulated storage.

\subsubsection{Storage}

Figure 8 shows the 1984-1999 mean monthly reservoir storages and daily time series at Grand Coulee and American Falls. At Grand Coulee, where downstream water requests are relatively small with respect to the annual flow, the simulated reservoir storage underestimates the amplitude of seasonal changes. However, the combined rules provide a realistic representation of the storage with a lower storage before the snowmelt peak for flood control and a sustained high storage during summer time for hydropower and irrigation when irrigation operating rules are used during summer.

The storage at American Falls is underestimated, although as shown later reservoir storage upstream (Palisades) agrees well with observations. Our model simulates major water requests from the dependent area of American Falls (Fig. 6) and upstream. In addition, the 1982-1999 mean annual flow shows high variability, with 1987-1992 being more than one standard deviation below the 1982-1999 annual mean while 1982-1984 and 1995-1997 are very wet. The Upper Snake observed demands are very large (Fig. 6) and is met 

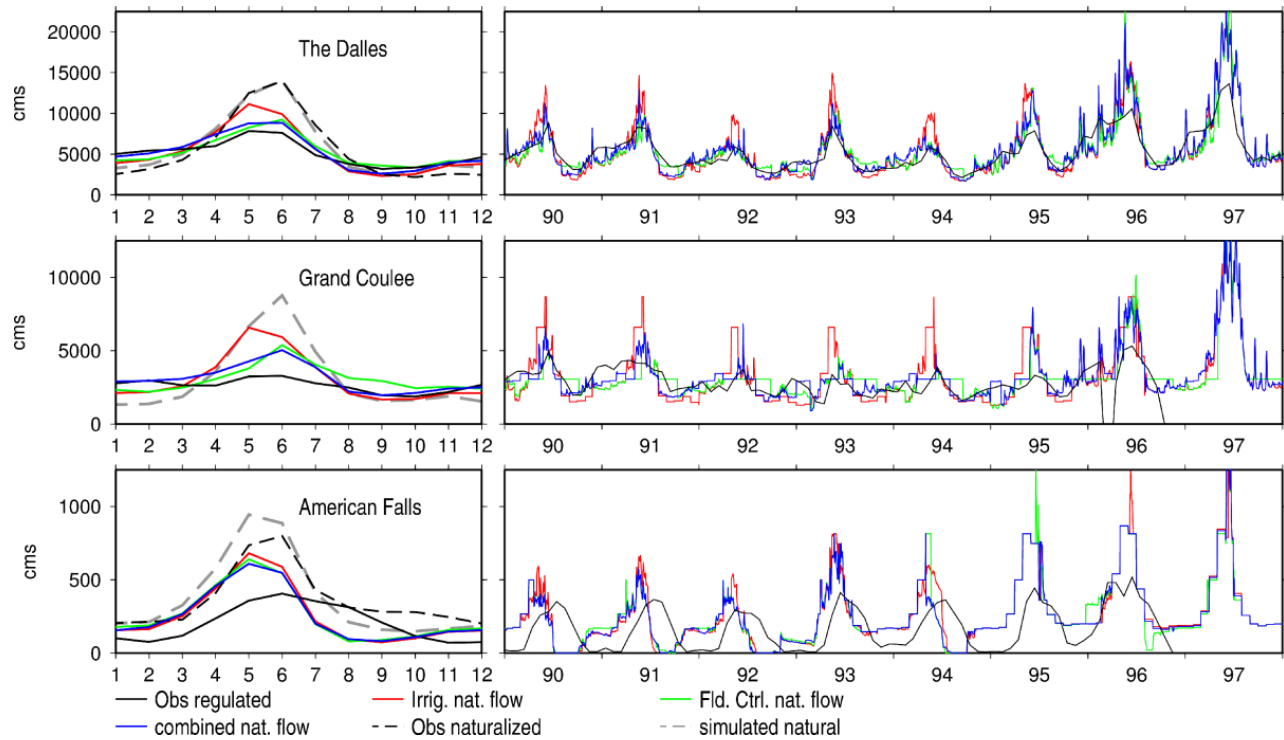

Fig. 7. Flow validation for operating rules using mean annual natural flow for the calibration.
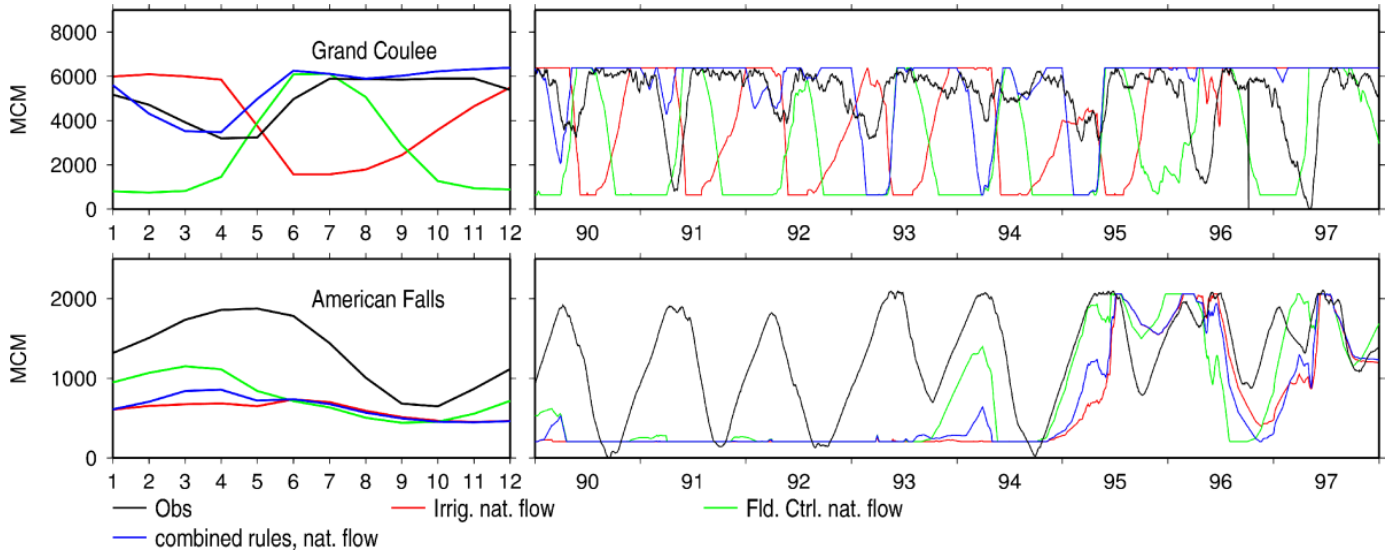

Fig. 8. 1984-1999 mean monthly average and daily timeseries of observed and simulated reservoir storage (millions cubic meter - MCM) at Grand Coulee and American Falls for operating rules with different priorities and calibrated with the mean annual natural flow.

in reality by a combination of surface water and a "flow augmentation approach" provided by groundwater withdrawals (USGS, 1994) (Fig. 10). The current setup, however, expects the demand to be met by surface water only. The combination of (i) high annual variability of the inflow into American Falls reservoir while the interannual variability in the releases is not specifically calibrated for such high variances, and (ii) an overestimated surface water demand over the Upper Snake River Basin, leads to overestimated releases (regulated flow overestimation) and in turn, to a dry-out of the reservoir storage.

\subsubsection{Supply}

As noted earlier, our simulation setup is driven by USGS observed consumptive demand. Figure 9 shows the basin av- erage USGS total consumptive demand converted to flow rate for evaluation of the demand with respect to the mean monthly flow. The total observed demand is not met, but this is consistent with the 2011 USGS report (Kenny et al., 2009), which noted that about $17 \%$ of the overall withdrawals is through groundwater pumping in the Pacific Northwest. Driven by demand and surface water, there are large interannual variabilities in the deficit. Figure 10 shows the spatial distribution of the fraction of the demand that cannot be met through surface water for the combined operating rules simulation. While over the northern and central part of the basin the observed demand is met, the Snake River stands out with fractions ranging from 0.05 to 0.60 . The region relies heavily on extensive groundwater pumping (USGS, 2011 and Fig. 10) from aquifers overlapping regions outside of the Columbia River Basin to supply for irrigation. Assuming that 
Table 4. Performance metrics for simulated 1983/10 to 1999/09 monthly regulated flow for the nine experiments at three locations: the Dalles, Grand Coulee and American Falls.

\begin{tabular}{|c|c|c|c|c|c|c|}
\hline Location & Predictors & Priority & Correlation & NSE & relative bias & relative RMSE \\
\hline \multicolumn{7}{|c|}{ The Dalles } \\
\hline & N/A & N/A & 0.96 & 0.91 & 1.06 & 0.23 \\
\hline & \multirow[t]{3}{*}{ Natural Flow, withdrawals } & Irrigation & 0.95 & 0.27 & 1.04 & 0.34 \\
\hline & & Flood Control & 0.93 & 0.58 & 1.04 & 0.26 \\
\hline & & Combined & 0.95 & 0.62 & 1.03 & 0.24 \\
\hline & \multirow[t]{3}{*}{ Regulated Flow, withdrawals } & Irrigation & 0.94 & -0.03 & 1.04 & 0.40 \\
\hline & & Flood Control & 0.94 & 0.35 & 1.04 & 0.32 \\
\hline & & Combined & 0.95 & 0.38 & 1.04 & 0.31 \\
\hline & \multirow[t]{3}{*}{ Regulated Flow, consumptive } & Irrigation & 0.94 & -0.01 & 1.04 & 0.40 \\
\hline & & Flood Control & 0.94 & 0.35 & 1.04 & 0.32 \\
\hline & & Combined & 0.95 & 0.39 & 1.04 & 0.31 \\
\hline \multicolumn{7}{|c|}{ Grand Coulee } \\
\hline & \multirow[t]{3}{*}{ Natural Flow, withdrawals } & Irrigation & 0.80 & -1.81 & 1.06 & 0.51 \\
\hline & & Flood Control & 0.77 & -0.63 & 1.06 & 0.39 \\
\hline & & Combined & 0.85 & -0.11 & 1.06 & 0.32 \\
\hline & \multirow[t]{3}{*}{ Regulated Flow, withdrawals } & Irrigation & 0.79 & -2.54 & 1.05 & 0.57 \\
\hline & & Flood Control & 0.78 & -1.33 & 1.05 & 0.46 \\
\hline & & Combined & 0.84 & -0.78 & 1.05 & 0.40 \\
\hline & \multirow[t]{3}{*}{ Regulated Flow, consumptive } & Irrigation & 0.79 & -2.48 & 1.05 & 0.57 \\
\hline & & Flood Control & 0.78 & -1.34 & 1.05 & 0.46 \\
\hline & & Combined & 0.84 & -0.72 & 1.05 & 0.40 \\
\hline \multicolumn{7}{|c|}{ American Falls (84-99) } \\
\hline \multirow[t]{10}{*}{$(84-92)$} & N/A & N/A & 0.87 & 0.64 & 0.91 & 0.4 \\
\hline & \multirow[t]{3}{*}{ Natural Flow, withdrawals } & Irrigation & 0.81 & -0.35 & 1.17 & 0.82 \\
\hline & & Flood Control & 0.79 & -0.43 & 1.18 & 0.84 \\
\hline & & Combined & 0.80 & -0.30 & 1.15 & 0.80 \\
\hline & \multirow[t]{3}{*}{ Regulated Flow, withdrawals } & Irrigation & 0.83 & -0.47 & 1.10 & 0.85 \\
\hline & & Flood Control & 0.79 & -0.80 & 1.16 & 0.94 \\
\hline & & Combined & 0.81 & -0.64 & 1.12 & 0.90 \\
\hline & \multirow[t]{3}{*}{ Regulated Flow, consumptive } & Irrigation & 0.80 & -0.61 & 1.11 & 0.89 \\
\hline & & Flood Control & 0.79 & -0.77 & 1.17 & 0.93 \\
\hline & & Combined & 0.79 & -0.72 & 1.13 & 0.92 \\
\hline
\end{tabular}
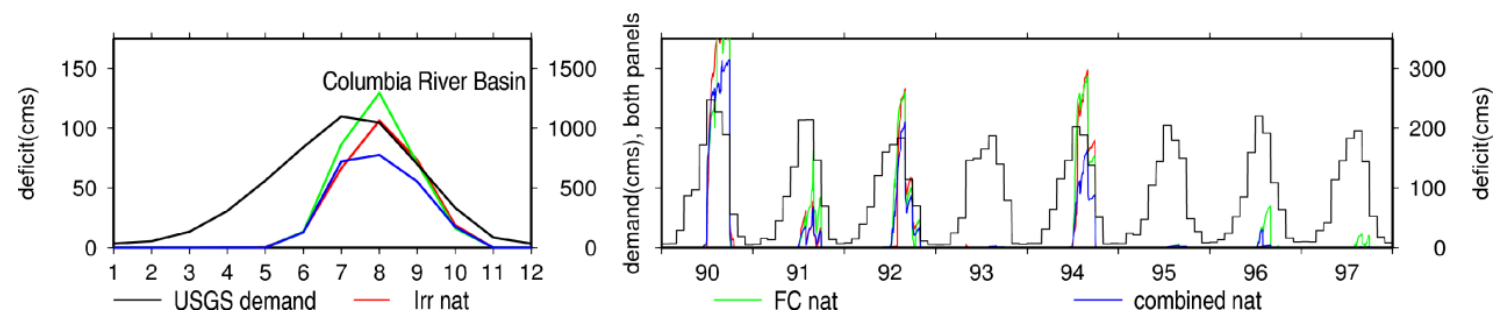

Fig. 9. 1984-1999 mean monthly and daily time series of USGS total consumptive demand (middle axis) and the supply deficit (exterior axis) as simulated by the reservoir module. 


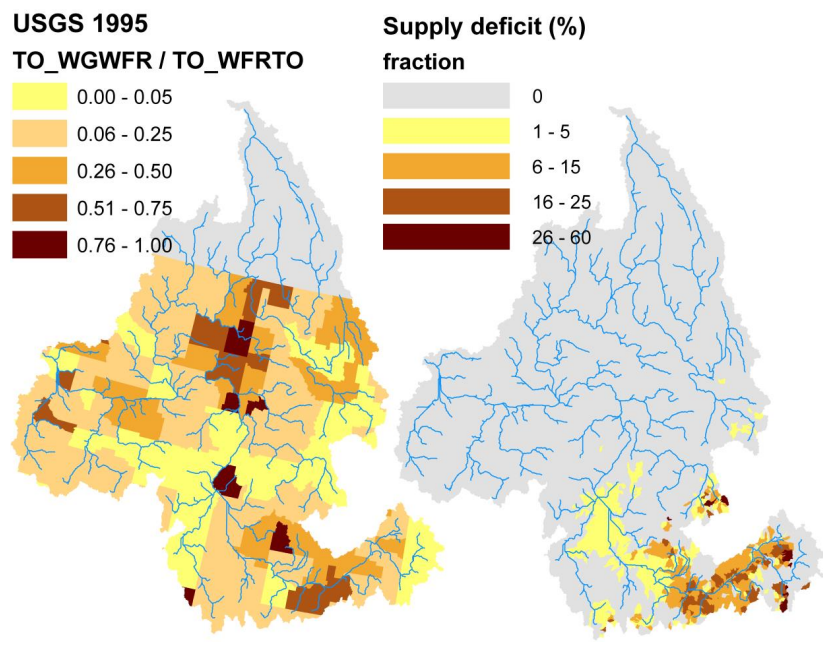

Fig. 10. (left) Reported fraction of withdrawals relying on groundwater; (right) simulated percentage of the annual demand that is not met.

the demand that cannot be met through the surface water system can be met by groundwater is a reasonable assumption. Hence, groundwater should be considered before the reservoirs dry up in future implementation of the water management model, for a more accurate representation of the anthropogenic influence on the hydrologic cycle.

\subsection{Sensitivity to operating rules priorities}

We evaluate the sensitivity of WM to operating priorities and demonstrate the improvement of the combined operating rules by evaluating the errors in regulated flow, storage and supply with respect to observations for different priorities WM set ups: irrigation, flood control and combined.

\subsubsection{Flow}

Figure 7 shows the 1984-1999 mean monthly outflow and daily outflow time series at The Dalles, Grand Coulee and American Falls for multiple priority rules for the baseline predictors (natural flow and withdrawals). Overall, all simulated regulated flows capture the change from the observed natural to regulated flow at The Dalles and Grand Coulee, showing reduced flow mainly between May and July after the flood control period ends and before the operational year begins. When irrigation is the priority in the operation rules, the flow reduction begins in June instead of May, so the peak of the regulated flow is shifted a month earlier compared to when flood control or combined flood control and irrigation are used as priorities and compared less favorably with the observed regulated flows. Table 4 compares performance metrics showing highest or equivalent correlation coefficients, NSE and lowest mean errors for the combined operating rules at all three locations, regional and sub-regional.

\subsubsection{Storage}

Figure 8 shows the 1984-1999 mean monthly reservoir storages and daily time series at Grand Coulee and American Falls. Two types of results are noted. At Grand Coulee the simulated reservoir storage using flood control and irrigation operating rules have about the right amplitude of changes. However, they are out of phase with the observations either in term of refill or drop. Therefore, individual rules do not allow for a realistic representation of multiple objectives and are not appropriate for water quality modeling or estimate of local evaporation feedback into the atmosphere.

\subsubsection{Supply}

Figure 9 shows the basin average USGS total consumptive demand and supply deficit for multiple priority rules. The combined operating rules setup agrees the most with observed supply because the summer supply deficit is lower by about 50 and $30 \%$ with respect to the flood control and irrigation operating rules respectively.

\subsection{Sensitivity to predictors}

The sensitivity to predictors is evaluated for all three operating rules priority configurations so that the interactions between priority and predictors can also be evaluated.

Figure 11 summarizes the sensitivities of the mean monthly flow, storage and supply deficit as seen earlier for operating rules calibrated with an estimated mean annual impounded flow (dashed line) in lieu of the unregulated flow (solid line), and with consumptive demand instead of withdrawals for calibrating the rules (circles).

\subsubsection{Flow}

The regulated flow at the regional scale (The Dalles) shows higher snowmelt peaks when using mean annual regulated instead of natural flow for flood control and combined priority rules. There is little sensitivity to the use of either withdrawals or consumptive demand because the overall extraction is not that large. At the sub-regional scale, the regulated flows show similar little sensitivities as the regional scale. Changing from using the mean annual unregulated flow to the estimated impounded annual flow (lower inflow due to upstream extractions) for setting up the operation rules leads to releases of smaller amplitude over the entire year (Eqs. 1, 2 and 4, Fig. 11, evaluating "nat" with "reg"), which decreases the agreement with the observed regulated flows (Table 4). Figure 11 more explicitly illustrates the effect of using different flows as predictors and priorities for Grand Coulee. Similarly the change consisting of using the consumptive use (evaporative demand from crop for example) instead of the withdrawals affects the monthly climatology of the releases as the monthly anomalies decrease (Eq. 2, evaluating "reg" with "reg consum"), but the effects are generally very small. 

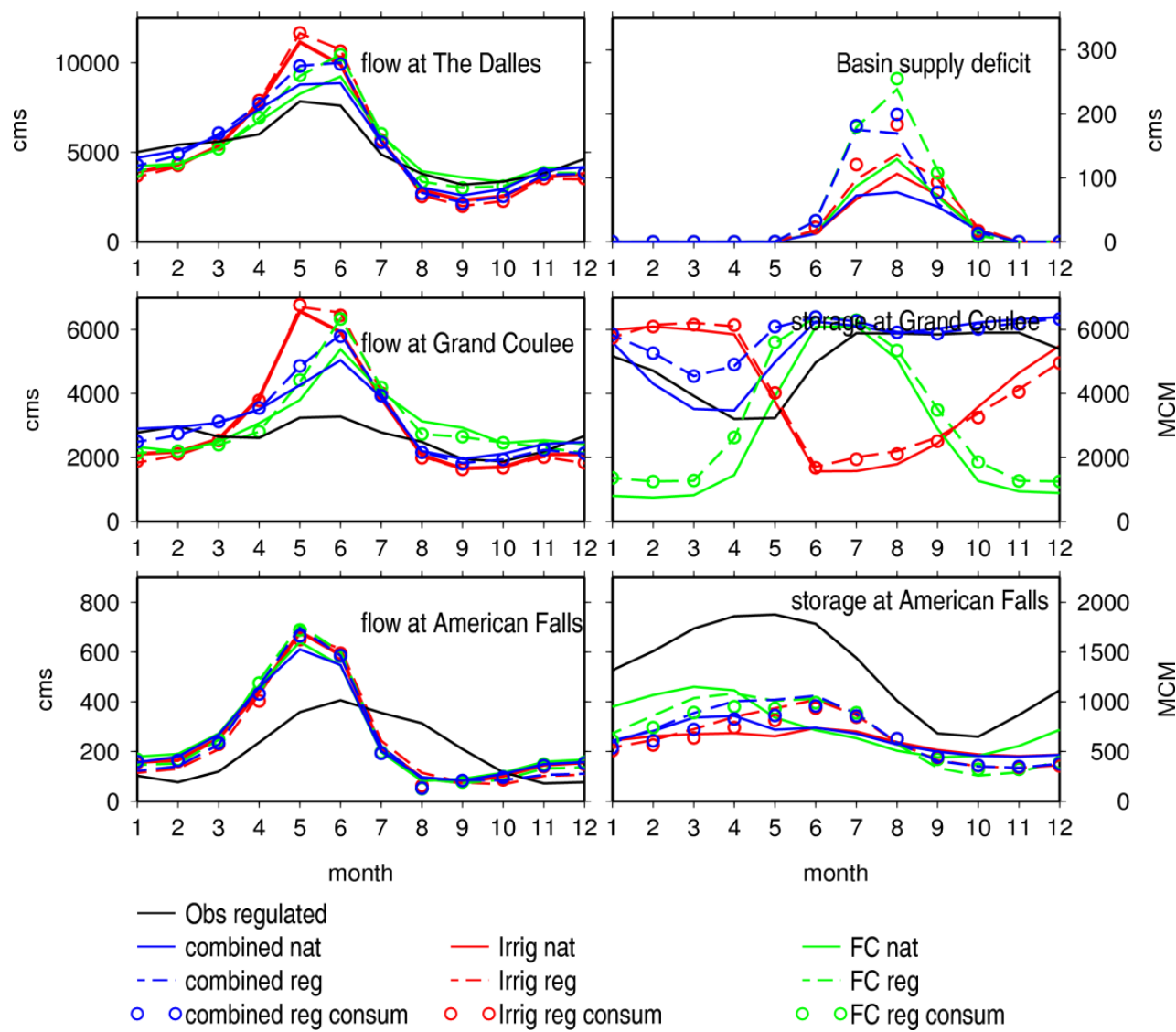

$$
\begin{aligned}
& \text { — Irrig nat } \\
& -- \text { Irrig reg } \\
& \circ \text { olrrig reg consum }
\end{aligned}
$$

$$
\begin{aligned}
& \text { - FC nat } \\
& --F C \text { reg } \\
& \circ \quad \text { FC reg consum }
\end{aligned}
$$

Fig. 11. Sensitivity of the flow, storage and supply with respect to using estimated annual regulated flow instead of naturalized flow for calibrating the rules, and using consumptive use instead of withdrawals for calibrating the monthly variability of the operating rules.

\subsubsection{Storage}

The largest sensitivity to predictors lies in the storage simulations. At Grand Coulee, for the flood control or irrigation priority rules there is no clear improvement or deterioration of performance relative to the observed out-of-phase storage variations. For the combined priorities operating rules, the storage simulation (storage targets) has a decreased performance when using the annual regulated inflow (Table 4). Figure 12 shows a detailed analysis of sensitivity of 29 reservoirs operated jointly for irrigation and flood control to the source of the mean annual flow. Overall, using the mean annual regulated flow lead to almost constantly full reservoirs and frequent uncontrolled spills for reservoirs of smaller capacity than Grand Coulee. At American Falls where extractions are very large with respect to the mean annual flow, the use of annual regulated flow allows a brief refill of the reservoir during snowmelt peak flows when it previously was kept dry due to larger releases. The use of regulated mean annual flow at American Falls is a potential improvement, for storage only. In addition, the largest uncertainty at American Falls remains in the demand estimates where a large fraction should rely in reality on the groundwater systems.

\subsubsection{Supply}

We note that the overall supply deficit is larger when using the regulated mean annual flow especially when flood control (and combined rules) is used as priority, and to a lesser extent when consumptive use instead of withdrawals for irrigation (and combined rules) is used as priority due to the decrease in monthly variability in the operating rules and less supply available in summer time (Eq. 2 and Fig. 11).

\section{Discussion}

Numerical experiments have been designed to isolate the uncertainties in different implementations of generic operating rules in a reservoir model. The definition of the rules has been improved by combining the irrigation release targets with flood control storage targets, which is important for reservoirs that serve multiple objectives. The use of withdrawals as predictor in the release targets has been shown to provide higher monthly variability in the flow releases and best agreements with observations in terms of flow, storage and water supply. A couple of remaining sources of uncertainties have been identified that need to be discussed: the uncertainties 

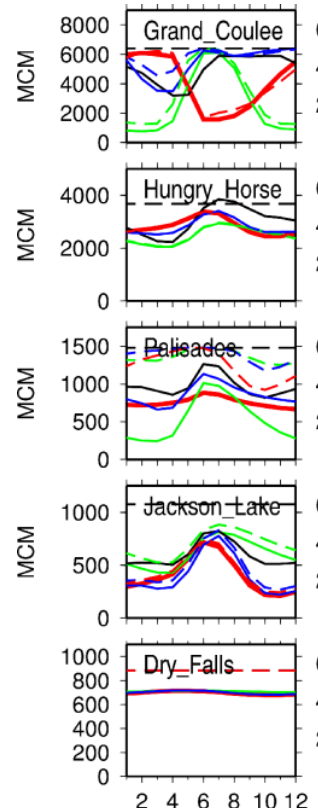

0

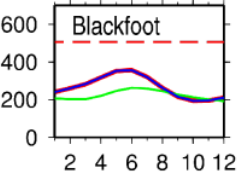

- Obs

- - Irrig. nat. flow

- Irrig. reg. flow
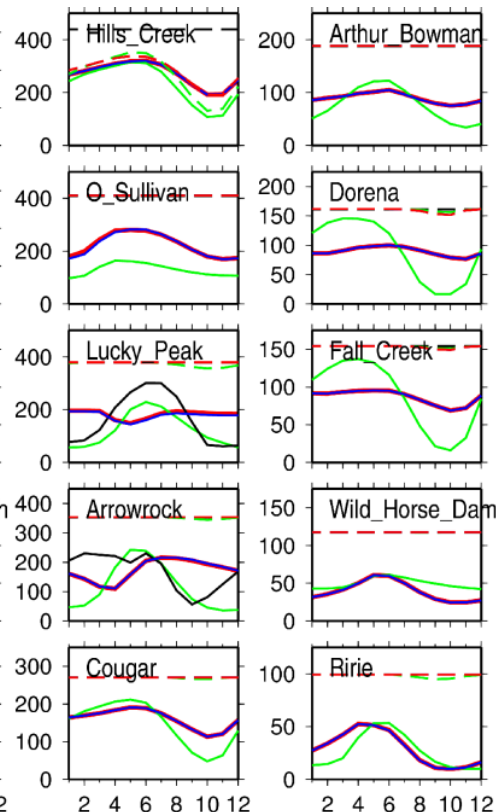

- - Max. Capacity

— Fld. Ctrl. nat. flow

- Fld. Ctrl. reg. flow
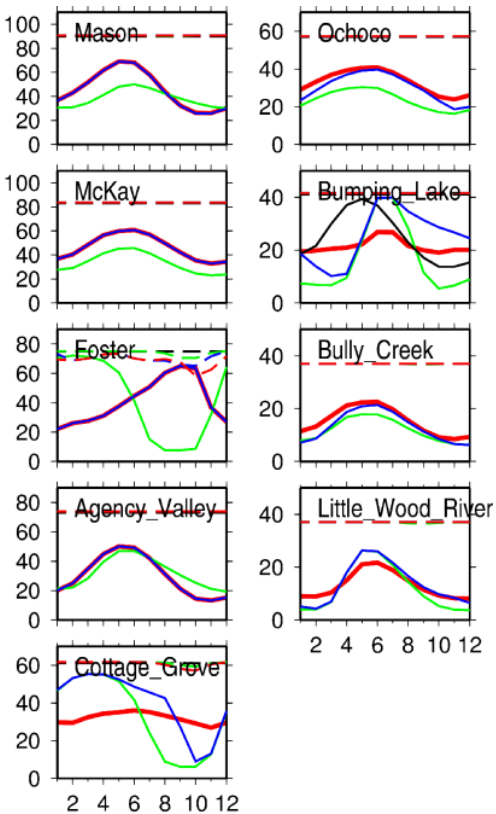

- combined rules, nat. flow

- - combined rules, reg. flow

Fig. 12. Sensitivity of the storage with respect to using estimated annual regulated flow instead of naturalized flow for calibrating the rules for calibrating the monthly variability of the operating rule for the 29 reservoirs operated conjointly for irrigation and flood control (blue in Fig. 3).

in the reservoir dependency database, the use of mean annual regulated or unregulated flow for setting up the operating rules, and the contribution of groundwater supply that is not accounted for in this study.

\subsection{Reservoir dependency uncertainties}

There are multiple uncertainties in the dependency database partly already described in the reservoir database description. In brief:

on the representation of areas dependent on a reservoir, our approach is consistent with approaches that have been applied and published. A more sophisticated approach has also been tested initially; the dependent subbasins would lie (i) downstream of the reservoirs but (ii) subbasins along the tributary rather than the main stem must be within $200 \mathrm{~km}$ of the river reach and (iii) the minimum elevation within each subbasin is lower than the actual elevation rather than the grid cell mean elevation of the reservoir. This additional restriction does not lead to significant improvement with respect to the coarse approach and is computationally much more intensive for global applications. Using grid-based or subbasins representations and different grid cell sizes should overall provide equivalent simulated flows and water supply, but the spatial distribution of the supply might change with more or less grid cells/subbasins (edge of buffers) allowed to extract water from the reservoirs.
The prorating of each subbasin's demand to reservoir (dependent area database) uses the storage of the reservoirs at the beginning of the month, equivalent to Haddeland et al. (2006a). Biemans et al. (2011) used an equivalent portioning based on a running past $20 \mathrm{yr}$ mean annual inflow into the reservoirs, which requires an on-the-fly estimates to avoid pre-processing. The authors experimented with prorating using the long-term mean monthly natural inflow into each reservoir, but could not find much difference compared to the present results at the regional scale.

Biemans et al. (2011) performed a sensitivity analysis of the reservoir model operations (withdrawals) with respect to the dependent area by varying the buffer from the main stem, and with respect to the portioning by varying reservoir capacities; "Decreasing the size of the buffer from five 0.5-degree gridcell (equivalent to our current $200 \mathrm{~km}$ buffer) to two led to a decrease in the withdrawals of $-17 \%$ while increasing the buffer size to eight grid cells increased the withdrawals by $3 \%$. Similarly, the portioning of the demand was evaluated by multiplying or dividing the capacity of the reservoir by two, which led to the largest sensitivities in the computation of the withdrawals $( \pm 20 \%)$ ". Using an equivalent dependency database allowed fair comparison of the reservoir operating rules of the existing reservoir model setups. 


\subsection{Natural or regulated mean annual flow as predictor}

In Sect. 4.3, we showed that over basins where the overall extraction is relatively small with respect to the mean annual unregulated flow, the best performing implementation is not the use of the mean annual regulated flow but rather the use of the mean annual natural flow for the derivation of operation rules. This is because there are large uncertainties in the annual regulated flow, which is derived in a pre-processing step based on the simulated mean annual natural inflow and the estimate of mean annual demand associated with reservoir upstream of Grand Coulee. This estimate is subject to uncertainties in the reservoir dependency database, as well as dependent area and prorating and errors in the simulated annual natural inflow. In basins where extractions are not large with respect to the mean annual inflow, sensitivity to the mean annual unregulated or regulated flows are large. Therefore, uncertainties in the reservoir dependency database can lead to large differences in reservoir storage, which might make the use of regulated flow for calibration of the operating rules less skillful in basins with relatively small extractions. In this implementation, the reservoir model reproduces the regulated flow in reasonable agreement with the observed regulated flow - although more improvement could perhaps be achieved by accounting for more interannual variability. The largest improvement is a more realistic reservoir storage simulation, which gives confidence in the overall distribution of the water supply and how it will return to both the river flow - return flow - and to the atmosphere via evapotranspiration fluxes when fully coupled with an ESM.

\subsection{Groundwater supply}

Over basins where extractions are very large, most often groundwater is an important source of water supply. Previous simulations have attempted to give a range of uncertainty by comparing simulations without groundwater supply or by assuming that all remaining demand was fully met by groundwater (Haddeland et al., 2006b; Doell et al., 2009; Biemans et al., 2011). We showed here that those two implementations without any and with complementing groundwater supply are both leading to dry reservoirs and will most likely results in errors in the spatial and temporal distribution of the supply, which in turn lead to errors in the return flow estimates and evapotranspiration fluxes. Errors will come from the evaporation over the reservoirs themselves, but also from the fact that surface water is extracted first, leading to dry reservoirs upstream and forcing downstream subbasins like those over the Snake River Basin to rely on groundwater. The estimate of how much certain areas rely on groundwater to meet the demand will necessitate research in particular if advances in more local climate, water quality and energy modeling are envisioned.

\section{Conclusions}

Existing generic operating rules for reservoir operations that are calibrated only with the long-term mean monthly flow hydrograph and demand associated with the reservoir have been further investigated in this work. Although generic operating rules do not optimize reservoir operations for multiple purposes, they do not require multiple runs within one time step or knowledge of the forecasted or observed future flow at multiple locations within the basin. Therefore, they are most appropriate for implementation in Earth system models. We evaluated different offline model set-ups to develop a framework for improving both the operating rules and also their potential implementation in ESMs.

The existing set ups for different reservoir operations modules differ in many ways including not only the definition of and terms in operating rules definition (terms) but also in the use of priority of reservoir usage and predictors for the operating rules.

Our overall findings are:

- Validation of the reservoir module through evaluating not only the regulated flow, but also the demand met and the reservoir storage, allows sources of errors to be isolated and uncertainties from the reservoir model and the hydrologic simulations (without vegetation growth and irrigation module components) to be assessed. This analysis allowed the development of storage targets to complement release targets in order to improve WM.

- Evaluation of the model:

- Over a basin with a well calibrated hydrology model, WM captures relatively well the impoundment of the flow, i.e. regulation and extraction, regionally and subregionally.

- A good agreement between the simulated and observed natural flow is necessary as the mean annual flow is the main driver in the operating rules; a systematic bias - equivalent to using the mean annual regulated flow - leads to the largest differences in simulated supply, reservoir storage and regulated flow. The next larger source of errors is the operating rules, i.e. the reservoir model structure as seen on the storage simulation and water supply mostly. Errors in the demand were minimized as we used observed demand, but still can be significant with the inclusion of both surface water and groundwater demand in the total term. Errors in the reservoir dependency database can be large locally, but are reasonable at the subregional and regional scale. 
This model leverages largely from Biemans et al. (2011) model using irrigation as priority rules and consumptive use and regulated flow as predictors. In turn Biemans et al. (2011) leverage largely from Hanasaki et al. (2006) who used flood control as the priority rule and natural flow and withdrawals for predictors. Recommendations for the optimal WM configurations are given as follows:

- Rules priority:

Operating rules that combine flood control storage targets and irrigation release targets improve the simulation of regulated flow at the regional and subregional scales for reservoirs that serve multiple objectives. Reservoir storage simulations are also significantly improved, giving confidence to the spatio-temporal distribution of the water supply, and hence return flow and evapotranspiration fluxes estimates in future simulations. The current improvement provided by the combined operating rules is expected to be the largest in basins that are snowmelt controlled - for its specific high monthly variability - and for which flood control is operationally a constraint for providing extensive irrigation, hydropower and other supply during the subsequent dry period. Combining flood control storage targets with water supply purpose was a necessary improvement for applications such as climate change assessment where snowmelt and flood control operations are likely to be significantly impacted, or for water quality modeling. The storage targets could be further improved in future work by (i) adjusting multiple flood control periods and (ii) implementing a nonlinear drop of the reservoir storage based on snow information.

- Predictors:

1. Withdrawals rather than consumptive demand should be used in the calibration of the generic operating rules, in particular for reservoirs with a priority for irrigation (i.e. no flood control). The releases targets are sensitive to the use of withdrawals rather than consumptive demand for calibrating the monthly variability of the releases. Higher monthly variability allows more consumptive use to be met.

2. Over basins where the overall extraction is relatively small with respect to the mean annual unregulated flow (on the order of reasonable calibrated annual bias), the best performing implementation is the use of the combined priorities operating rules using the mean annual natural flow and the mean monthly withdrawals for their calibration.

3. Over basins where the overall extraction is large but groundwater is not a major supply, the best performing implementation of the rules is anticipated to be the implementation just described but using the estimated mean annual impounded flow instead. However, this result may not be generalized and requires further investigations in the future.

- Groundwater over basins where the overall extraction is large and the groundwater system is known to complement the surface water system, or vice-versa, the largest errors come from not including an estimate of the fraction of the demand that should be met, in priority, by groundwater. Assuming that all the remaining demand can be met by groundwater implies conserving the errors in the surface water system simulations. Research is recommended in this area for advancing estimates of return flow and more accurate dependence on groundwater.

The analysis was performed over the Columbia River Basin at both regional and subregional scales to cover multiple hydro-meteorological conditions; The basin is highly snowmelt controlled in the main stem, and many tributaries are snow-rain transition basins with a monthly hydrograph having two peaks in the late Fall and in the Spring, with a transition period not falling below the mean annual flow and with very dry Summer. The basin-scale system is operated for extensive irrigation, flood control, hydropower and other demands for water supply. Similar improvement and sensitivities results are expected in other places with similar flow regime and water management characteristics.

Acknowledgements. This study was performed as part of the Integrated Earth System Modeling (iESM) project supported by Department of Energy Earth System Modeling program to develop models for representing the influence of human-earth system interactions on the water and carbon cycles. The Pacific Northwest National Laboratory (PNNL) Platform for Regional Integrated Modeling and Analysis (PRIMA) Initiative supported the development of databases used in reservoir modeling and some analyses of the results. PNNL is operated by Battelle for the U.S. Department of Energy under contract DE-AC05-76RLO1830. The authors thank the anonymous reviewers for their helpful comments and suggestions.

Edited by: F. Pappenberger

\section{References}

Biemans, H., Haddeland, I., Kabat, P., Ludwig, F., Hutjes, R. W. A., Heinke, J., von Bloh, W., and Gerten, D.: Impact of reservoirs on river discharge and irrigation water supply during the 20th century, Water Resour. Res., 47, W03509, doi:10.1029/2009WR008929, 2011

Degu, A. M., Hossain, F., Niyogi, D., Pielke Sr., R., Shepherd, J. M., Voisin, N., and Chronis, T.: The Influence of Large Dams on Surrounding Climate and Precipitation Patterns, Geophys. Res. Lett., 38, L04405, doi:10.1029/2010GL046482, 2011. 
Doell, P., Fiedler, K., and Zhang J.: Global-scale analysis of river flow alterations due to water withdrawals and reservoirs, Hydrol. Earth Syst. Sci., 13, 2413-2432, doi:10.5194/hess-13-24132009, 2009.

Elsner, M. M., Cuo, L., Voisin, N., Deems, J. S., Hamlet, A. F., Vano, J. A., Mickelson, K. E. B., Lee, S. Y., and Lettenmaier, D. P.: Implications of 21 st Century climate change for the hydrology of Washington State, Clim. Change, 102, 225-260, doi:10.1007/s10584-010-9855-0, 2010

Haddeland, I., Lettenmaier, D. P., and Skaugen, T.: Effects of irrigation on the water and energy balances of the Colorado and Mekong River basins, J. Hydrol., 324, 210-223, 2006a

Haddeland, I., Skaugen, T., and Lettenmaier, D. P.: Anthropogenic impacts on continental surface water fluxes, Geophys. Res. Lett., 33, L08406, doi:10.1029/2006GL026047, 2006b

Haddeland, I., Skaugen, T., and Lettenmaier, D. P.: Hydrologic effects of land and water management in North America and Asia: 1700-1992, Hydrol. Earth Syst. Sci., 11, 1035-1045, doi:10.5194/hess-11-1035-2007, 2007.

Hanasaki, N., Kanae, S., and Oki, T.: A reservoir operation scheme for global river routing models, J. Hydrol., 327, 22-41 doi:10.1016/j.jhydrol.2005.11.011, 2006.

Hanasaki, N., Kanae, S., Oki, T., Masuda, K., Motoya, K., Shirakawa, N., Shen, Y., and Tanaka, K.: An integrated model for the assessment of global water resources - Part 1: Model description and input meteorological forcing, Hydrol. Earth Syst. Sci., 12, 1007-1025, doi:10.5194/hess-12-1007-2008, 2008a.

Hanasaki, N., Kanae, S., Oki, T., Masuda, K., Motoya, K., Shirakawa, N., Shen, Y., and Tanaka, K.: An integrated model for the assessment of global water resources - Part 2: Applications and assessments, Hydrol. Earth Syst. Sci., 12, 1027-1037, doi:10.5194/hess-12-1027-2008, 2008b.

Kenny, J. F., Barber, N. L., Hutson, S. S., Linsey, K. S., Lovelace, J. K., and Maupin, M. A.: Estimated use of water in the United States in 2005, US Geological Survey Report, Circular 1344, available at: http://pubs.usgs.gov/circ/1344/, 2009.

Labadie, J.: MODSIM: River basin management decision support system, Chapter 23 in: Watershed Models, edited by: Singh, V. and Frevert, D., CRC Press, Boca Raton, Florida, 2005.

Li, H., Wigmosta, M. S., Wu, H., Huang, M., Ke, Y., Coleman, A. M., and Leung, L. R.: A Physically Based Runoff Routing Model for Land Surface and Earth System Models, J. Hydrometeorol., 14, 808-828, doi:10.1175/JHM-D-12-015.1, 2013.

Liang, X., Lettenmaier, D. P., Wood, E. F., and Burges, S. J.: A Simple hydrologically Based Model of Land Surface Water and Energy Fluxes for GSMs, J. Geophys. Res., 99, 14415-14428, 1994.
Lehner, B., Reidy Liermann, C., Revenga, C., Vörösmary, C., Fekete, B., Crouzet, P., Döll, P., Endejan, M., Frenken, K., Magome, J., Nilsson, C., Robertson, J. C., Rödel, R., Sindorf, N., and Wisser, D.: High resolution mapping of the world's reservoirs and dams for sustainable river flow management, Front. Ecol. Environ., 9, 494-502, 2011.

Maurer, E. P., Wood, A. W., Adam, J. C., Lettenmaier, D. P., and Nijssen, B.: A long-term hydrologically-based data set of land surface fluxes and states for the conterminous United States, J. Climate, 15, 3237-3251, 2002.

Moore, B., Wigmosta, M., and Coleman, A.: Development of a national spatio-temporal water use dataset with application to energy production, in preparation, 2013.

Payne, J. T., Wood, A. W., Hamlet, A. F., Palmer, R. N., and Lettenmaier, D. P.: Mitigating the effects of climate change on the water resources of the Columbia River basin, Clim. Change, 62, 233-256, 2004.

Pokhrel, Y., Hanasaki, N., Koirala, S., Cho, J., Yeh, P. J.-F., Kim, H., Kanae, S., and Oki, T.: Incorporating Anthropogenic Water Regulation Modules into a Land Surface Model, J. Hydrometeor., 13, 255-269, doi:10.1175/JHM-D-11-013.1, 2012a.

Pokhrel, Y., Hanasaki, N., Yeh, P. J.-F., Yamada, T. J., Kanae, S., and Oki, T.: Model estimates of sea-level change due to anthropogenic impacts on terrestrial water storage, Nat. Geosci., 5, 389-392, 2012b.

Sheer, D. P.: OASIS OCL. Hydrologics, Inc., Columbia MD, 2000.

Siebert, S., Döll, P., Hoogeveen, J., Faures, J. M., Frenken, K., and Feick, S.: Development and validation of the global map of irrigation areas, Hydrol. Earth Syst. Sci., 9, 535-547, doi:10.5194/hess-9-535-2005, 2005.

Solley, W. B., Pierce, R. R., and Perlman, H. A.: Estimated use of water in the United States in 1998, US Geological Survey Report, Circular 1200, available at: http://water.usgs.gov/watuse/ pdf1995/html/, 1999.

USGS: GROUND WATER ATLAS of the UNITED STATES, Idaho, Oregon, Washington, HA 730-H, edited by: Whitehead, R. L., available at: http://pubs.usgs.gov/ha/ha730/ch_h/index.html, 1994.

Yates, D. : WEAP21 - A demand-, priority- and preference-driven water planning model: Part 1, model characteristics, Water International, 30, 501-512, 2005.

Zagona, E., Fulp, T., Shane, R., Magee, T., and Goranflo, H.: RiverWare: A Generalized Tool for Complex Reservoir Systems Modeling, J. Am. Water Resour. Assoc., AWRA, 37, 913-929, 2001. 